\title{
A gene responsible for autosomal dominant auditory neuropathy (AUNA1) maps to 13q14-21
}

\author{
T B Kim, B Isaacson, T A Sivakumaran, A Starr, B J B Keats, M M Lesperance
}

J Med Genet 2004;41:872-876. doi: 10.1136/jimg.2004.020628

$\mathrm{H}$ earing loss is most commonly defined as either conductive, affecting the sound conduction mechanism comprised of the external auditory canal, tympanic membrane, and middle ear ossicles, or sensorineural (SNHL), affecting the cochlea, the auditory nerve, or the central auditory pathway. However, the recent discovery that outer hair cells (OHC) generate otoacoustic emissions (OAEs) has allowed differentiation of sensory hearing loss (in which OAEs are absent) from neural hearing loss, which is caused by a lesion of inner hair cells and/or the auditory nerve. The hallmark of auditory neuropathy (AN), a neural type of hearing loss, is preservation of OAEs and abnormal or absent auditory brainstem responses. ${ }^{1}$ Most patients with SNHL are found to have a sensory type of hearing loss, and numerous genes for both syndromic and non-syndromic forms have been identified (Hereditary Hearing Loss Homepage, http:// www.uia.ac.be/dnalab/hhh/). However, none of the approximately 50 dominant (DFNA) loci are known to represent an auditory neuropathy phenotype.

AN may accompany peripheral neuropathy in a variety of dominant syndromes such as Charcot-Marie-Tooth disease ${ }^{2}$ and Freidreich's ataxia. ${ }^{3}$ AN unassociated with peripheral neuropathy most commonly occurs as a sporadic or recessive trait, ${ }^{4-6}$ but $X$ linked recessive ${ }^{6}$ and autosomal dominant ${ }^{7}$ forms have also been described. We have mapped a gene responsible for autosomal dominant auditory neuropathy in a multigenerational family from the United States to a novel locus, AUNAl (auditory neuropathy, dominant, 1) on 13q14-21.

\section{METHODS}

The family is of European descent and was ascertained through two different probands by both the University of Michigan and the University of California at Irvine. The Institutional Review Boards of the University of Michigan Medical School, Louisiana State University Health Sciences Center, and the University of California at Irvine approved the study, and informed consent was obtained from all subjects. Four generations were available for study, including 47 family members informative for genetic analysis of whom 33 were affected, four were unrelated spouses, and 10 were unaffected (fig 1). All unaffected members were at least 18 years old. Two individuals (VI:9 and VI:13) had isolated high frequency sensorineural hearing loss consistent with their sex and age and were characterised as unaffected prior to linkage analysis. Information was obtained from questionnaires and interviews with family members. Standard pure tone audiometry was performed for all participants, and peripheral blood or buccal cell samples were obtained. The phenotype was extensively characterised by otologic and neurologic examination and by audiological, psychoacoustic, and neurophysiological testing. ${ }^{8}$ SLINK analysis predicted an average maximum LOD score of 7.90 , with $100 \%$ of replicates greater than 3.0.9 ${ }^{10}$

\section{Key points}

- Auditory neuropathy (AN) is a type of hearing loss defined by the preservation of outer hair cell function and abnormal or absent auditory brainstem responses. We studied 47 members of a family of European descent from the United States segregating autosomal dominant non-syndromic AN.

- AUNA1 maps to a $5.47 \mathrm{cM}$ interval on chromosome 13q14-21 between D13S153 (centromeric) and D13S1317 (telomeric). Two individuals homozygous for the haplotype common to affected family members did not appear to be more severely affected than the heterozygotes. The maximum two point LOD score was 9.87 at $\theta=0.019$ for D13S153.

- We conclude that AUNAl is the first locus found responsible for autosomal dominant AN. Assessment of outer hair cell function by otoacoustic emissions or cochlear microphonics will clarify the prevalence of AN in non-syndromic deafness families.

Genomic DNA was isolated from peripheral blood lymphocytes and buccal epithelial cell samples using standard methodology. A genome scan was performed by the Center for Inherited Disease Research (CIDR, http://www.cidr.jhmi. $\mathrm{edu} /$ ) as an automated fluorescent microsatellite analysis using a marker set of approximately 400 primer pairs with average spacing of $10 \mathrm{cM}$. Two point LOD scores assuming complete penetrance, gene frequency of 0.00001 , and $0 \%$ phenocopy rate were calculated using the MLINK and ILINK programs from the LINKAGE package. ${ }^{11}$

Fine mapping was performed by genotyping additional markers on chromosome 13 (fig 1) through the University of Michigan Sequencing Core. Allele frequencies and sizes were calculated by comparing the genotypes of CEPH individual 1347-02 to the CEPH genotype database (http://www. cephb.fr). To avoid overstated evidence for linkage caused by underestimation of marker allele frequencies, the allele frequency for the linked allele was not allowed to be less than 0.1 .

\section{RESULTS}

The hearing loss was inherited as an autosomal dominant trait with an average age of onset of 18.6 years. There were

Abbreviations: $A B R$, auditory brainstem responses; $A N$, auditory neuropathy; CIDR, Center for Inherited Disease Research; CMs, cochlear microphonics; ENU, $\mathrm{N}$-ethyl- $\mathrm{N}$-nitrosurea; OAEs, otoacoustic emissions; $\mathrm{OHC}$, outer hair cell; SNHL, sensorineural hearing loss; WS, Wolfram syndrome 


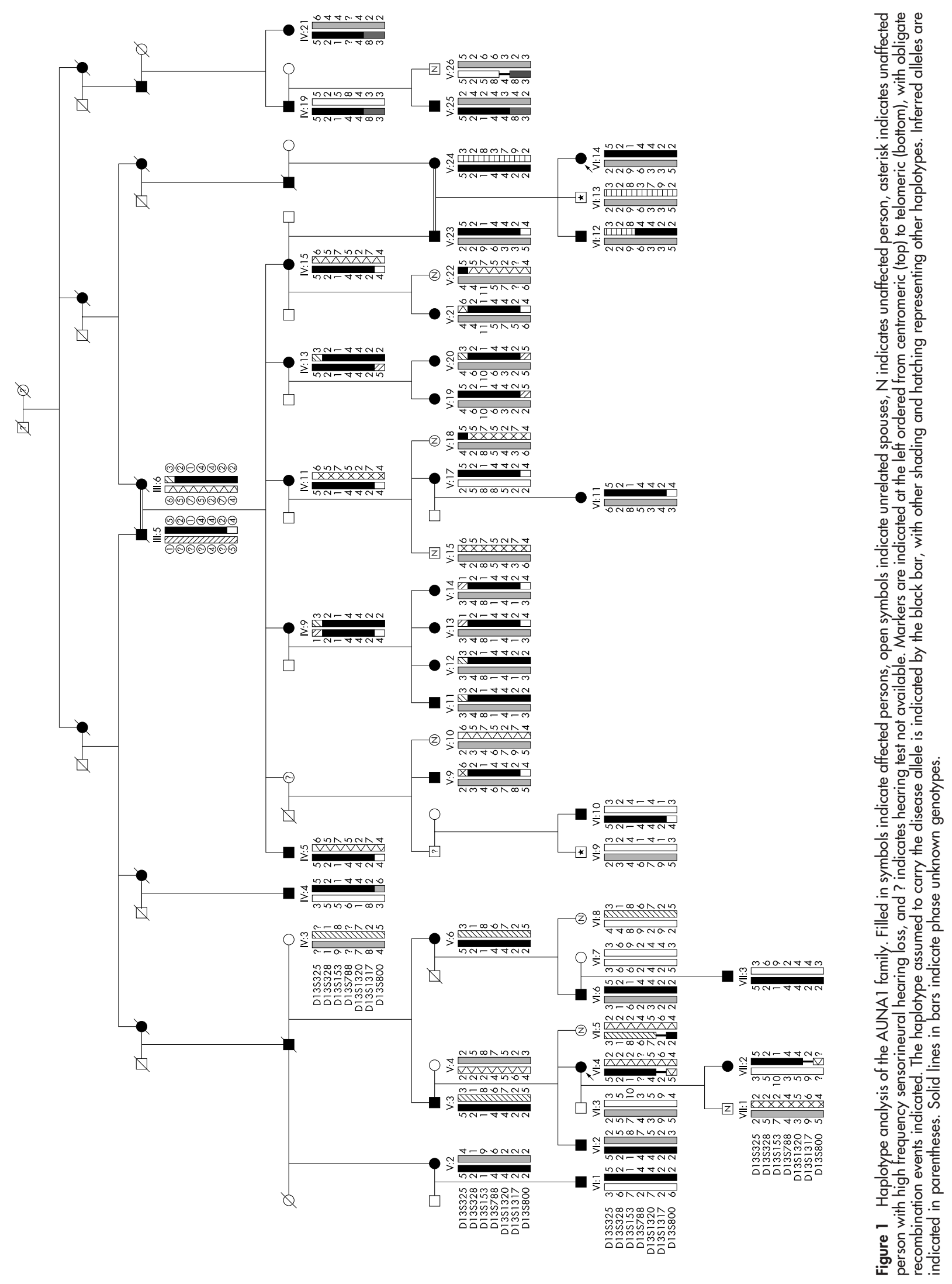


two consanguineous marriages in the family, one between affected first cousins (III:5 and III:6) and the other between affected second cousins (V:23 and V:24). Of seven affected offspring available for study from these consanguineous marriages, two (IV:9 and IV:13) were found to be homozygous for the haplotype common to the affected family members. However, with the exception of an age of onset at the lower end of the range ( 8 and 9 years for IV: 9 and IV:13, respectively), there were no apparent clinical features differentiating their phenotype from that of the heterozygotes.

The youngest affected family members presented with auditory neuropathy, defined as preserved OHC function (as documented by normal distortion product OAE responses), and hearing loss documented by pure tone audiometry and/or auditory brainstem response (ABR). Over time, OAEs disappeared and thresholds increased, diagnostic of profound sensorineural hearing loss. No evidence of cranial or peripheral neuropathies was found. The results of the haplotype analysis were consistent with our assumption of complete penetrance after age 18, even though some individuals reported onset as late as 45 years of age. However, for most participants, the age of onset was estimated based on that individual's recollection. Affected family members presented with a range of phenotypes which will be described elsewhere. ${ }^{8}$ Intrafamilial variability is quite common even for hereditary hearing loss segregating as a simple Mendelian trait, most likely due to environmental and secondary genetic factors. ${ }^{12}$

The maximum two point LOD score was 9.87 at $\theta=0.019$ for D13S153 (table 1). No recombination events were observed for D13S788 (LOD $=7.91$ at $\theta=0$ ) or D13S1320 $(\mathrm{LOD}=9.33$ at $\theta=0)$. A recombination event between D13S153 and D13S788 in individual VI:12 defines the centromeric end of the interval (fig 1). The telomeric end of the interval is defined by an obligate recombination event that occurred between D13S1320 and D13S1317, transmitted to individuals IV:19, IV:21, and V:25. The interval between D13S153 (centromeric) and D13S1317 (telomeric) spans $5.47 \mathrm{cM}$ in 13q14-21 (fig 2) as defined by recombination events in affected individuals only. The physical distance is approximately $18 \mathrm{Mb}$ (UCSC Genome Browser: http://genome. ucsc.edu). The locus was designated as AUNAl (http:// www.gene.ucl.ac.uk/nomenclature), and the interval does not overlap with other known human or murine deafness loci, corresponding to mouse chromosome 14 and a small portion of mouse 8 .

\section{DISCUSSION}

Great progress has been made in identifying genes responsible for non-syndromic hearing impairment, with at least 40 genes cloned and an equivalent number mapped for dominant, recessive, or $\mathrm{X}$ linked hearing loss (Hereditary Hearing Loss Homepage, http://www.uia.ac.be/dnalab/hhh/). Routine pure tone audiometry testing of both air and bone conduction can distinguish conductive from sensorineural hearing loss. However, very few studies of hereditary hearing impairment have measured OAEs or cochlear microphonics (CMs) to assess OHC function in affected subjects. Such testing is necessary to differentiate sensory hearing loss (caused by disorders of the cochlear outer hair cells) from neural hearing loss in which cochlear inner hair cells, the auditory nerve, and/or the synapses between inner hair cells and the auditory nerve are affected.

Patients with AN have absent or abnormal ABRs, absent middle ear reflexes, normal OAEs, and cochlear microphonic responses that invert with stimulus polarity. ${ }^{13}{ }^{14}$ Thresholds on pure tone audiometry may be normal or elevated to levels ranging from mild to profound hearing loss. Evidence suggests that some patients with AN are unlikely to benefit

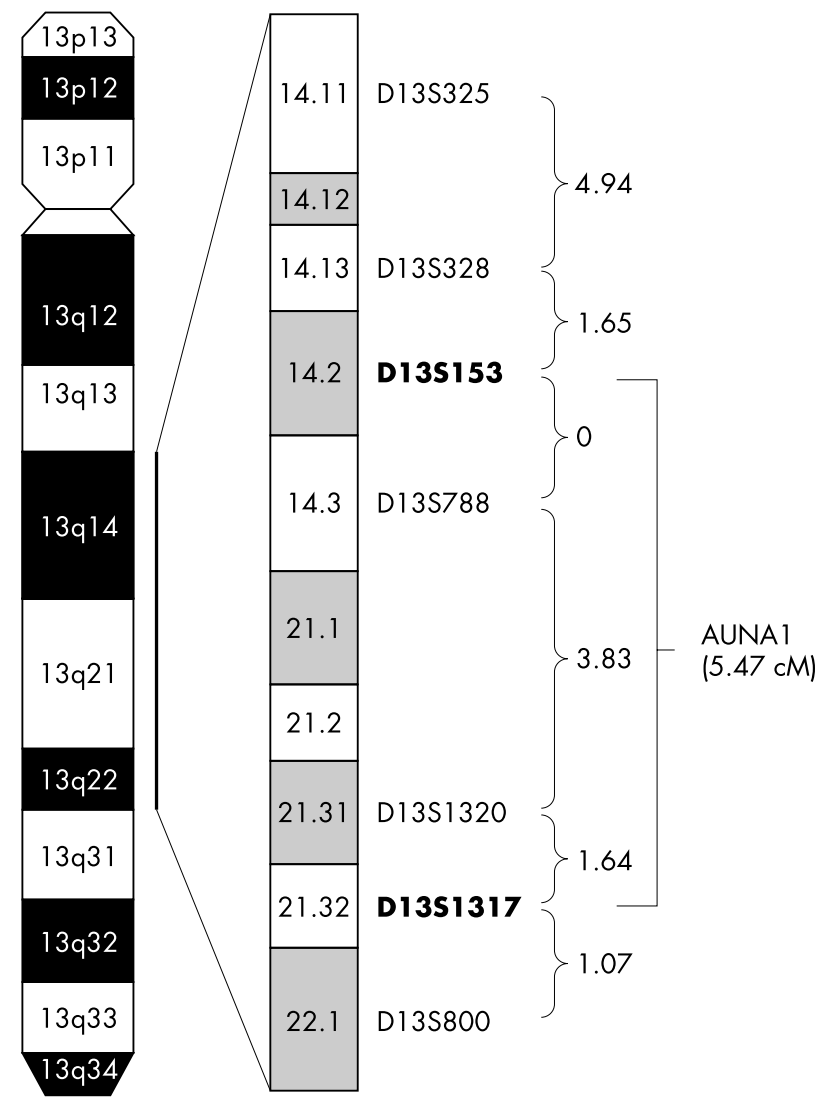

Figure 2 Ideogram of chromosome 13 indicating genotyped markers on 13q14-21 defining AUNA1 interval. Distances between markers are in centimorgans (cM) and were obtained from the Marshfield Center for Medical Genetics (http://research.marshfieldclinic.org/genetics/).

from hearing aids. ${ }^{14}{ }^{15}$ Approximately one third of patients with AN will ultimately demonstrate loss of OHC function to develop a true SNHL. ${ }^{16}$ Thus, OAEs, CMs, and ABRs must be tested early in life to recognise a hearing loss as AN.

Animal models of auditory neuropathy have been induced by carboplatin treatment of chinchillas ${ }^{17} 18$ and ouabain infusion in gerbil cochleas. ${ }^{19}$ Both Bronx waltzer (bv), a spontaneous mutant mapping to mouse chromosome $5,{ }^{20}$ and Beethoven (Bth), arising from $N$-ethyl- $N$-nitrosurea (ENU) mutagenesis of the tmcl gene, ${ }^{21}$ demonstrate inner hair cell loss preceding OHC loss. Patients with DFNA36 (MIM 606705) (Online Mendelian Inheritance in Man (OMIM), http://www.ncbi.nlm.nih.gov/Omim) or DFNB7/11 (MIM 600974) deafness caused by mutations of the human ortholog TMCl (MIM 606706) are not reported to have

\begin{tabular}{|c|c|c|c|c|c|c|c|}
\hline \multirow[b]{2}{*}{ Marker } & \multicolumn{5}{|c|}{ LOD score at $\theta=$} & \multirow[b]{2}{*}{$\theta$} & \multirow[b]{2}{*}{$Z_{\text {max }}$} \\
\hline & 0 & 0.1 & 0.2 & 0.3 & 0.4 & & \\
\hline D13S325 & $-\infty$ & 1.31 & 1.68 & 1.24 & 0.63 & 0.176 & 1.71 \\
\hline D13S328 & 7.57 & 5.84 & 4.16 & 2.54 & 1.07 & 0 & 7.57 \\
\hline D13S153 & $-\infty$ & 8.69 & 6.49 & 4.09 & 1.78 & 0.019 & 9.87 \\
\hline D13S788 & 7.91 & 6.11 & 4.27 & 2.46 & 0.87 & 0 & 7.91 \\
\hline D13S1320 & 9.33 & 7.33 & 5.29 & 3.27 & 1.42 & 0 & 9.33 \\
\hline D13S1317 & $-\infty$ & 4.66 & 3.50 & 2.12 & 0.85 & 0.05 & 4.93 \\
\hline D13S800 & $-\infty$ & -0.68 & 0.04 & 0.15 & 0.13 & 0.324 & 0.15 \\
\hline
\end{tabular}


auditory neuropathy, ${ }^{22}$ but neither OAEs nor CMs were tested in these families (A Griffith, personal communication).

Mutations in the otoferlin (OTOF, MIM 603681) gene, first identified as the cause of DFNB9 (MIM 601071), appear to be a common cause of non-syndromic autosomal recessive AN. ${ }^{523} \mathrm{AN}$ in conjunction with Charcot-Marie-Tooth disease has been attributed to mutations in the myelin protein zero (MPZ, MIM 159440), peripheral myelin protein 22 (PMP22, MIM 601097), gap junction protein, beta l (GJBl, MIM 304040), and early growth response 2 (EGR2, MIM 129010) genes. ${ }^{24}$ In addition, mutations in the N-myc downstream regulated gene (NDRGl, MIM 605262) gene are associated with the autosomal recessive disorder known as hereditary motor and sensory neuropathy-Lom. Acquired or environmental causes of AN include neonatal hyperbilirubinemia, ${ }^{25}$ anoxia, and prematurity.

True dominance is exceedingly rare, as there is usually a more severe phenotype (for example, embryonic lethality) associated with homozygosity as compared to heterozygosity for a mutated allele. ${ }^{26}$ The notable exception is Huntington's disease (HD, MIM 143100), ${ }^{27}$ caused by abnormal expansion of triplet repeats. Non-syndromic hearing loss offers another example of an individual homozygous for a mutated allele that causes dominant hearing loss in both of his consanguineous parents. While Wolfram syndrome (WS, MIM 222300) is caused by homozygous and usually inactivating mutations in the WFSI (MIM 606201) gene, one patient homozygous for the A716T mutation in WFSI had only juvenile onset insulin dependent diabetes mellitus and cataracts ${ }^{28}$ without the optic atrophy necessary for a diagnosis of WS. A716T is one of many heterozygous missense mutations shown to cause non-syndromic dominant low frequency sensorineural hearing loss, DFNA6/14/38 (MIM 600965). ${ }^{29}$

We would predict that the mutation in this family will be found to be non-inactivating, for example, a missense mutation, rather than a null mutation resulting in haploinsufficiency. In the latter case, the complete lack of functional protein in the homozygotes would be expected to result in a more severe phenotype. Prospective clinical studies would be necessary to determine whether the homozygotes have an earlier age of onset. Although we could not identify any clinical features unique to the homozygous individuals in this study, identification of the AUNAl gene may suggest targets for clinical testing based on knowledge of the gene's function.

Numerous candidate genes of interest map to the AUNAl interval (UCSC Genome Browser: http://genome.ucsc.edu) including diaphanous homolog 3 (DIAPH3), several protocadherins (PCDH9 (MIM 603581), PCDH8 (MIM 603580), PCDH17, and PCHD20), and genes implicated in protein and/ or ion transport (WD repeat and FYVE domain containing 2 (WDFY2) and potassium channel regulator gene, KCNRG (MIM 607947)).

We report here a novel locus, AUNAl, which is responsible for progressive autosomal dominant auditory neuropathy in a large kindred from the United States. Our strategies to identify the AUNAl gene will include recruiting additional family members, genotyping additional markers in DNA samples from existing and new family members to look for new recombination events to further narrow the interval, and testing candidate genes within the interval. Identification of a gene responsible for auditory neuropathy will allow for genetic screening in sporadic cases or in families too small for genetic linkage analysis. In addition, assessing $\mathrm{OHC}$ function by OAE or CM testing in patients and families with non-syndromic hearing loss will lead to a better understanding of the variability among phenotypes.

\section{ACKNOWLEDGEMENTS}

We thank the family for their participation. We thank Laura Miller for assistance in preparation of the manuscript.

\section{Authors' affiliations}

T B Kim, B Isaacson, T A Sivakumaran*, M M Lesperance, Department of Otolaryngology-Head and Neck Surgery, University of Michigan Health System, Ann Arbor, MI 48109-0241, USA

A Starr, Department of Neurology, University of California at Irvine, Irvine, CA 92717, USA

B J B Keats, Department of Genetics, Louisiana State University Health Sciences Center, New Orleans, LA 70112, USA

This work was supported by grants from the National Institute on Deafness and Communication Disorders DC00161 (Lesperance) and DC02216 (Starr). Genotyping services were provided by the Center for Inherited Disease Research (CIDR) and the University of Michigan Sequencing Core. CIDR is fully funded through a federal contract from the National Institutes of Health to the Johns Hopkins University, Contract Number N01-HG-65403.

Conflict of interest: none declared.

${ }^{*}$ Current address: Department of Obstetrics and Gynecology, Brigham and Women's Hospital, Harvard Medical School, Boston, MA 02115, USA.

Correspondence to: Dr Marci M Lesperance, Division of Pediatric Otolaryngology, Department of Otolaryngology-Head and Neck

Surgery, F6905 Mott, Box 0241, 1500 East Medical Center Drive, Ann Arbor, Ml 48109-0241, USA; lesperan@umich.edu

Revised version received 30 April 2004

Accepted for publication 4 May 2004

\section{REFERENCES}

1 Starr A, Picton TW, Sininger $Y$, Hood $\amalg$, Berlin Cl. Auditory neuropathy. Brain 1996:1 19(Pt 3):741-53.

2 Satya-Murti S, Cacace AT, Hanson PA. Abnormal auditory evoked potentials in hereditary motor-sensory neuropathy. Ann Neurol 1979;5(5):445-8.

3 Satya-Murti S, Cacace A, Hanson P. Auditory dysfunction in Friedreich ataxia: result of spiral ganglion degeneration. Neurology 1980;30(10): 1047-53.

4 Madden C, Rutter M, Hilbert L, Greinwald JH Jr, Choo DI. Clinical and audiological features in auditory neuropathy. Arch Otolaryngol Head Neck Surg 2002;128(9): 1026-30.

5 Varga R, Kelley PM, Keats BJ, Starr A, Leal SM, Cohn E, Kimberling WJ. Nonsyndromic recessive auditory neuropathy is the result of mutations in the otoferlin (OTOF) gene. J Med Genet 2003;40(1):45-50.

6 Wang Q, Gu R, Han D, Yang W. Familial auditory neuropathy. Laryngoscope 2003;113(9):1623-9.

7 Bonfils P, Avan P, Londero A, Narcy P, Trotoux J. Progressive hereditary deafness with predominant inner hair cell loss. Am J Otol $1991 ; 12(3): 203-6$.

8 Starr A, Isaacson B, Michalewski HJ, Zeng F-G, Kong Y-Y, Beale P, Paulson GW, Keats BJB, Lesperance MM. A dominantly inherited progressive deafness affecting distal auditory nerve and hair cells, submitted.

9 Ott J. Computer-simulation methods in human linkage analysis. Proc Natl Acad Sci U S A 1989;86(11):4175-8.

10 Weeks D, OH J, Lathrop GM. SLINK: a general simulation program for linkage analysis. Am J Hum Genet 1990;47(suppl):A204.

11 Lathrop GM, Lalouel JM, Julier C, Ott J. Strategies for multilocus linkage analysis in humans. Proc Natl Acad Sci U S A 1984;81(11):3443-6.

12 Greene CC, McMillan PM, Barker SE, Kurnool P, Lomax MI, Burmeister M, Lesperance MM. DFNA25, a novel locus for dominant nonsyndromic hereditary hearing impairment, maps to 12q21-24. Am J Hum Genet 2001;68(1):254-60.

13 Berlin CI, Bordelon J, St John P, Wilensky D, Hurley A, Kluka E, Hood L. Reversing click polarity may uncover auditory neuropathy in infants. Ear Hear 1998;19(1):37-47.

14 Berlin Cl, Morlet T, Hood U. Auditory neuropathy/dyssynchrony: its diagnosis and management. Pediatr Clin North Am 2003;50(2):331-40, vii-viii.

15 Rance G, Beer DE, Cone-Wesson B, Shepherd RK, Dowell RC, King AM, Rickards FW, Clark GM. Clinical findings for a group of infants and young children with auditory neuropathy. Ear Hear 1999;20(3):238-52.

16 Sininger Y, Starr A, eds. Auditory neuropathy. San Diego: Singular Press, 2001

17 Harrison RV. An animal model of auditory neuropathy. Ear Hear 1998;19(5):355-61.

18 Salvi RJ, Wang J, Ding D, Stecker N, Arnold S. Auditory deprivation of the central auditory system resulting from selective inner hair cell loss: animal model of auditory neuropathy. Scand Audiol Suppl 1999;51:1-12. 
19 Schmiedt RA, Okamura HO, Lang H, Schulte BA. Ouabain application to the round window of the gerbil cochlea: a model of auditory neuropathy and apoptosis. J Assoc Res Otolaryngol 2002;3(3):223-33.

20 Bussoli TJ, Kelly A, Steel KP. Localization of the bronx waltzer (bv) deafness gene to mouse chromosome 5. Mamm Genome 1997;8(10):714-7.

21 Vreugde S, Erven A, Kros CJ, Marcotti W, Fuchs H, Kurima K, Wilcox ER, Friedman TB, Griffith AJ, Balling R, Hrabe De Angelis M, Avraham KB, Steel KP. Beethoven, a mouse model for dominant, progressive hearing loss DFNA36. Nat Genet 2002;30(3):257-8.

22 Kurima K, Peters LM, Yang Y, Riazuddin S, Ahmed ZM, Naz S, Arnaud D Drury S, Mo J, Makishima T, Ghosh M, Menon PS, Deshmukh D, Oddoux C Ostrer H, Khan S, Deininger PL, Hampton LL, Sullivan SL, Battey JF Jr, Keats BJ Wilcox ER, Friedman TB, Griffith AJ. Dominant and recessive deafness caused by mutations of a novel gene, $T M C 1$, required for cochlear hair-cell function. Nat Genet 2002;30(3):277-84.

23 Rodriguez-Ballesteros M, del Castillo FJ, Martin Y, Moreno-Pelayo MA Morera C, Prieto F, Marco J, Morant A, Gallo-Teran J, Morales-Angulo C, Navas C, Trinidad G, Tapia MC, Moreno F, del Castillo I. Auditory neuropathy in patients carrying mutations in the otoferlin gene (OTOF). Hum Mutat 2003;22(6):451-6.
24 Pareyson D. Charcot-Marie-Tooth disease and related neuropathies: molecular basis for distinction and diagnosis. Muscle Nerve 1999;22(1 1):1498-509

25 Stein LK. Maturation of the auditory system. Introduction. Ear Hear 1996; 17(5):359-60.

26 Nussbaum RL, Mclnnes RR, Willard HF, eds. Thompson \& Thompson Genetics in Medicine, 6th edn. Philadelphia: WB Saunders, 2001.

27 Wexler NS, Young AB, Tanzi RE, Travers H, Starosta-Rubinstein S, Penney JB, Snodgrass SR, Shoulson I, Gomez F, Ramos Arroyo MA, Penchaszadeh GK, Moreno H, Gibbons K, Faryniarz A, Hobbs S, Anderson MA, Bonilla E, Conneally PM, Gusella JF. Homozygotes for Huntington's disease. Nature 1987;326(6109): 194-7.

28 Young TL, Ives E, Lynch E, Person R, Snook S, MacLaren L, Cater T, Griffin A, Fernandez B, Lee MK, King MC, Cator T. Non-syndromic progressive hearing loss DFNA38 is caused by heterozygous missense mutation in the Wolfram syndrome gene WFS1. Hum Mol Genet 2001;10(22):2509-14.

29 Bespalova IN, Van Camp G, Bom SJ, Brown DJ, Cryns K, DeWan AT, Erson AE, Flothmann K, Kunst HP, Kurnool P, Sivakumaran TA, Cremers CW, Leal SM, Burmeister $M$, Lesperance MM. Mutations in the Wolfram syndrome 1 gene (WFS1) are a common cause of low frequency sensorineural hearing loss. Hum Mol Genet 2001; 10(22):2501-8. 